\title{
Adaptação intercultural: em busca de um modelo analítico
}

////////////////// Marcel Vieira Barreto Silva ${ }^{1}$ 


\section{Resumo}

Este artigo busca apresentar um debate teórico no campo dos estudos de adaptação, a fim de introduzir o conceito de adaptação intercultural e de propor um modelo analítico para esse tipo de investigação. Com isso, o texto pretende avançar nas discussões históricas sobre fidelidade/espírito da obra, a partir da elaboração de categorias formais capazes de demonstrar, na materialidade estilística de texto-fonte e filme adaptado, as transformações resultantes do processo adaptativo em que livro e filme pertencem a matrizes culturais diversas. Por fim, utilizaremos alguns exemplos de Shakespeare no cinema brasileiro para demonstrar a validade analítica das categorias propostas.

\section{Palavras-chave}

Adaptação intercultural, cinema e literatura, Shakespeare no cinema, cinema brasileiro.

Abstract

This paper intends to present a theoretical discussion in the field of adaptation studies, aiming to introduce the concept of intercultural adaptation and to propose an analytical model for this kind of investigation. With this, the text wants to advance the historical discussions about fidelity/ spirit of the work, by elaborating formal categories capable to demonstrate, in the stylistic materiality of the source-text and the adapted film, the transformations resultant of the adaptive process in which the book and the movie belong to different cultural patterns. At last, we will use some examples of Shakespeare in Brazilian cinema to demonstrate the analytical validity of the proposed categories.

\section{Keywords}

Intercultural adaptation, cinema and literature, Shakespeare on film, Brazilian cinema. 
2. Como não há indicação no texto da versão a que Woolf se refere, presume-se que, por questão temporal, ela esteja comentando uma das adaptações mudas, provavelmente de Pathé (1911) ou de Gardin (1914).

\section{Introdução}

A preocupação de entender as relações entre cinema e literatura é antiga e remonta às primeiras impressões que os críticos literários e os escritores tiveram ao verem tornados visuais os personagens e os espaços literários que cada qual, enquanto leitor individual, só conhecia mentalmente. Virginia Woolf (1950), por exemplo, criticava uma das adaptações fílmicas ${ }^{2}$ de Anna Karenina, romance do russo Leon Tolstoi, com o argumento de que o cinema parasitava a literatura ao não inventar ele próprio as suas histórias, tendo que, com isso, recorrer aos clássicos literários em busca de material expressivo. Assim, segundo a autora, se havia no cinema alguma pretensão de definir a sua especificidade própria, ele deveria se esforçar na criação de narrativas originais - e isso só seria possível pela experimentação das possibilidades específicas do novo meio.

Desse entendimento da relação entre cinema e literatura como parasitária e subserviente até chegar à ideia mais corrente hoje em dia, que entende o fenômeno a partir das noções de dialogismo (STAM, 1989, 2005) e intertextualidade (CORRIGAN, 1998; ALLEN, 2000; SANDERS, 2006), passaram-se não apenas inúmeros momentos de desenvolvimento e consolidação da linguagem cinematográfica como também diversos aportes teóricos que refletiram sobre o problema. Conceitos como os de fidelidade, essência/espírito e especificidade - que foram as categorias utilizadas nos primeiros estudos sobre cinema e literatura embora enfrentem resistência nas análises contemporâneas, foram fundamentais para a criação de um campo de estudos específico 
3. A referência aqui é precisamente ao texto "Por um cinema impuro: defesa da adaptação", mas vale também citar "Teatro e cinema", em que Bazin discorre sobre as dimensões realistas do cinema e sobre a importância da mise-en-scène para estabelecer diferenças entre as linguagens cinematográfica e teatral. sobre o tema. Aqui, vale destacar o papel pioneiro dos escritos de André Bazin (1991) sobre o assunto, que propuseram a criação de um discurso crítico em defesa da adaptação ${ }^{3}$. Se os primeiros analistas estavam mais preocupados em imprecar contra o cinema, considerando que ele vulgarizava os cânones literários da cultura erudita - tipo de análise que hoje soa deslocada e inoportuna —, atualmente, o campo de estudos abrange no seu espectro de análises não somente espécies literárias mais ligadas ao consumo massivo e popular mas também a multiplicidade de diálogos que cinema e literatura estabelecem em termos temáticos, estilísticos e formais. Aqui, vale lembrar o trabalho fundamental de Linda Hutcheon (2006), em que a teórica e crítica canadense busca analisar a adaptação como um fenômeno cultural mais amplo, que envolve produtos tão diversos como a literatura, os videogames, a ópera e os parques temáticos. Essa visão ajuda a entender o processo adaptativo para além do jogo binário entre texto-fonte e obra adaptada, permitindo averiguar as dimensões extratextuais que participam do processo como um todo - e, aqui, a dimensão da cultura parece central para a definição dos aspectos interculturais de um espectro mais abrangente de adaptações cinematográficas.

Historicamente, percebemos que as motivações de levar a literatura canônica para o cinema foram muitas, porém uma razão se destaca, por ter sido um movimento consciente e coordenado em favor da adaptação fílmica: a busca dos produtores e dos exibidores de cinema, a partir da segunda metade da primeira década do século XX, por um público burguês letrado, com poder aquisitivo para transformar o espetáculo cinematográfico em um evento menos popular e mais elitista (COSTA, 1995; MACHADO, 2007). Os produtores queriam evitar a censura dos órgãos governamentais, que começavam a ver no cinema um lugar de promiscuidade e desordem, e os exibidores queriam deixar os filmes mais rentáveis, aumentando os preços dos ingressos e tornando as salas de cinema em ambientes mais familiares. Para isso, uma ação articulada foi adaptar os cânones da literatura clássica, apresentando-os como espetáculos moralizantes, de alto valor cultural, que atraísse as plateias letradas e o seu poder aquisitivo mais elevado. 
A partir de então, a literatura passou a ser presença cada vez mais constante no cinema, em variados níveis. Para investigar as particularidades dessa presença, o campo de estudos de cinema e literatura possui, convencionalmente, três grandes tipos de abordagem, que, embora não excludentes, possuem recortes de análise próprios: os estudos estilísticos, os estudos históricos e os estudos de caso. Nos estudos estilísticos, o foco de análise é o modo como a literatura influenciou (e ainda influencia) a criação e o desenvolvimento da linguagem cinematográfica, seja no seu viés clássico-narrativo, seja no recorte mais específico do cinema experimental e de vanguarda.

É esse tipo de estudo que verifica o modo como a literatura está presente no cinema (e vice-versa) de diversas formas. Um exemplo é a visão de que o cinema narrativo teria se apropriado de um repertório expressivo e genérico da literatura, a fim de construir sua linguagem própria (BORDWELL, 1985). A elipse, a montagem paralela, a metonímia imagética, a sucessão de cenas temporal e espacialmente separadas, o ritmo, os personagens e os diálogos, a instância narrativa e a manipulação de pontos de vista elementos estruturais do que se convencionou chamar de cinema clássico-narrativo - podem ser encontrados na literatura, seja ela narrativa, seja ela dramática, seja ela poética, muito tempo antes de os irmãos Lumière realizarem os seus primeiros experimentos com imagem em movimento. Em autores como Dickens, Flaubert, Homero, Shakespeare, Dante, Molière, Dostoiévski e Henry James, respectivamente, esses elementos ocupam lugar privilegiado na estrutura formal de cada um, destacando-se enquanto dado estético da especificidade literária.

No segundo tipo, os estudos históricos, a relação entre cinema e literatura aprofunda o recorte diacrônico de análise, investigando como um período na história de uma cinematografia ou mesmo um diretor específico se relacionam com a literatura. É o caso, para falar de um exemplo consagrado, da relação entre o Cinema Novo e a literatura modernista/romance de 1930 (DEBBS, 2007), ou da presença da literatura no cinema brasileiro da retomada (SILVA, 2009). É o caso também dos estudos que selecionam os trabalhos 
de um autor específico, ou mesmo um livro em particular, e analisam diacronicamente todos os filmes realizados a partir deles, destacando o percurso histórico realizado por essas obras. Os autores do chamado cânone literário, como Shakespeare, Jane Austen, Dickens e, aqui no Brasil, Machado de Assis, Guimarães Rosa, Nelson Rodrigues e Clarice Lispector, são objetos privilegiados nesse tipo de estudo.

No terceiro tipo, os estudos de caso, encontramos o mais amplo escopo de análises, em termos quantitativos, referente ao campo de estudos de cinema e literatura. Nessa forma de investigação, consolidou-se a utilização de uma metodologia comparativa que posiciona lado a lado o texto-fonte e o filme adaptado, a fim de estabelecer diferenças e semelhanças, formais e temáticas, resultantes do processo adaptativo. Certamente, é esse tipo de estudo que representa em abrangência o caráter interdisciplinar que define o campo: atualmente, os estudos de adaptação são comuns no Brasil em programas de pós-graduação ligados tanto a departamentos de letras quanto a de comunicação e de cinema, reafirmando, com isso, a utilização de categorias e procedimentos metodológicos oriundos das três áreas.

No caso deste artigo, buscaremos definir categorias analíticas específicas (língua falada, trama, cronótopo, dominantes genéricas e estilo de encenação), dentro do campo da análise estilística, a fim de investigar os processos adaptativos em que texto-fonte e filme adaptado não pertencem a uma mesma matriz cultural, configurando, assim, um tipo específico de adaptação, que chamaremos aqui de adaptação intercultural.

Se, por exemplo, colocarmos lado a lado filmes realizados a partir de Hamlet, teremos obras tão diversas como realizações homônimas de Laurence Olivier (1948), Tony Richardson (1969), Celestino Coronada (1976), Franco Zeffirelli (1990), Kenneth Branagh (1996) e Michael Almereyda (2000); versões interculturais na Índia (dir. Sohrab Modi, 1935), na Rússia (dir. Grigori Kozintsev, 1964), em Gana (dir. Terry Bishop, 1964), no Canadá (dir. René Bonnière e Stephen Bush, 1973) e na China (dir. Sherwood Hu, 2006); filmes considerados "adaptações mais livres", como Hamlet: 
The drama of vegeance (dir. Sven Gade, 1920), Homem mal dorme bem (dir. Akira Kurosawa, 1960) e Hamlet liikemaailmassa (dir. Aki Kaurismäki, 1987); e obras mais radicalmente paródicas, como Rosencrantz and Guildenstern are dead (dir. Tom Stoppard, 1990) e Hamlet 2 (dir. Andrew Fleming, 2009); além dos inúmeros filmes silenciosos que representavam uma cena ou uma sequência célebre da peça. Trata-se de uma diversidade tão ampla de meios, estilos e culturas que se torna difícil imaginar um conceito de adaptação que unifique essa gama de variações em torno de uma idéia unitária.

Além dessa grande variedade de exemplos concretos, as teorias em torno da adaptação cinematográfica costumam esquecer um elemento fundamental na compreensão do processo como um todo: a dimensão do leitor/espectador. Como aponta Linda Hutcheon (2006), adaptação pode ser definida por três perspectivas que, embora distintas, são intimamente relacionadas: primeiramente, uma adaptação é uma entidade formal, ou um produto, isto é, "uma transposição extensiva e anunciada de uma ou mais obras em particular" (HUTCHEON, 2006, p. 7). Nesse sentido, uma adaptação cinematográfica é um filme concreto, que transpõe para a linguagem audiovisual um conjunto de elementos originários de um texto literário declarado.

Em um segundo sentido, uma adaptação é compreendida como um processo de criação, que "sempre envolve (re)interpretação e, em seguida, (re)criação; isso tem sido chamado ora apropriação ou salvação, dependendo da sua perspectiva" (HUTCHEON, 2006, p. 8). Ou seja, chamamos de adaptação cinematográfica não apenas a obra concreta mas todo processo criativo do qual o filme resulta. No processo de adaptação, nesse sentido, estão implicadas inúmeras variáveis estéticas, culturais, sociais, econômicas e políticas, cada qual desempenhando um papel específico nas escolhas criativas que serão impressas no filme.

Aqui, a compreensão do que é uma adaptação pertence a uma dimensão mais ampla, não restritiva à análise formal comparativa entre o texto-fonte e o filme adaptado. É precisamente esse conceito que ajuda a relacionar, no caso das adaptações cinematográficas, o discurso fílmico em sua materialidade a todas as variáveis 
extrafílmicas que atuam na produção e no consumo das obras. Exemplo disso são os motivos - desde os estritamente econômicos até os mais radicalmente políticos - que levam determinados realizadores a adaptar certos textos literários, com procedimentos estilísticos, estilos e projetos autorais particulares.

Um terceiro e último sentido entende a adaptação como um processo de recepção, no sentido de que a relação entre livro-filmeleitor/espectador (não necessariamente nessa mesma ordem) só se completa quando há conhecimento - e mesmo engajamento do leitor/espectador em relação tanto ao texto-fonte quanto ao filme adaptado. "Nós experimentamos as adaptações (como adaptações) como palimpsestos através da nossa memória de outras obras que ressoam através da repetição com variação" (HUTCHEON, 2006, p. 8). Isso significa que uma adaptação cinematográfica, para ser entendida e apreciada como tal, necessita fundamentalmente que o indivíduo que assiste ao filme conheça o livro, ou que, visto o filme, procure ler o livro. É nesse espectro de questões que podemos refletir sobre o público de uma adaptação como fãs (HUTCHEON, 2006, p. 116), mobilizados pelo engajamento entre um objeto de afeição (um romance, uma ópera, um videogame ou uma graphic novel) e a sua transposição para o cinema. Sem a presença do receptor, alguém conhecedor do texto-fonte (antes ou após o consumo do filme adaptado), o processo de adaptação não se completa em todas as suas dimensões.

Podemos então chegar a um conceito de adaptação que considere as diversas variáveis envolvidas em sua realização, desde a produção até o consumo, ou seja: adaptação é tanto o processo quanto o resultado da criação de uma obra artística a partir de uma fonte reconhecível de outro meio de expressão. No caso de uma adaptação da literatura para o cinema, estamos falando de um filme realizado a partir de um texto literário, cujas marcas são visíveis o suficiente para serem identificadas. Aqui, os elementos centrais que estão envolvidos no processo adaptativo em sua amplitude parecem destacados: primeiro, trata-se de um processo de criação, 
realizado por motivações diversas, que implicam escolhas estéticas particulares; segundo, é o resultado desse processo de criação, em cuja materialidade estão inscritas as escolhas feitas durante o processo; terceiro, necessita de uma fonte reconhecível, pois é necessário que o leitor-espectador esteja engajado, em maior ou menor grau, em ambas as obras; e, por fim, implica necessariamente em uma mudança de meio de expressão.

Diante desse conceito de adaptação, mais irrestrito e geral, podemos pensar no tipo específico de adaptação que nos interessa aqui, em que texto-fonte e filme adaptado pertencem a matrizes culturais diversas e que chamaremos de adaptação intercultural. Acreditamos, com isso, que há não apenas uma especificidade estilística nesse tipo de adaptação mas sobretudo uma necessidade de reavaliação epistemológica, visto que não podemos analisar a relação entre filme e livro adaptado simplesmente através de categorias textuais comparativas - base dos estudos de adaptação, a partir da incorporação dos conceitos de transtextualidade de Genette (1982). Ao contrário, devemos utilizar o choque cultural como um prisma que direciona as ferramentas textuais para transformações deliberadas. Com isso, damos também um passo além da leitura clássica da adaptação, seja pela perspectiva da fidelidade - hoje já devidamente relativizada — , seja pela crítica fenomenológica que trabalha com a ideia de espírito da obra, categoria essa que escorrega diante de sua ambição hermenêutica mais abrangente.

Antes de chegar a um conceito próprio de adaptação intercultural, deparamo-nos com uma série de questões teóricas, cujas respostas vão nos auxiliar no nosso objetivo: como definir a adaptação intercultural e quais são as suas especificidades? Que operações e procedimentos estilísticos são utilizados nesse processo? Qual o seu lugar na história da teoria e da prática da adaptação? E, finalmente, de que forma os pressupostos teóricos da adaptação intercultural ajudam a entender os filmes adaptados por seus próprios méritos? É no esforço de responder a essas questões que se estrutura este artigo. 


\section{Adaptação intercultural: da possibilidade}

\section{teórica ao estabelecimento de categorias de análise}

Antes detudo, devemos justificar a escolha pelotermo “intercultural”, em detrimento de outras categorias, como multicultural ou transcultural, enfatizando sua melhor exequibilidade analítica. Para isso, estamos corroborando o caminho teórico de Patrice Pavis (2008), no seu estudo sobre o teatro no entrecruzamento de culturas. Para Pavis, o teatro da contemporaneidade tem se valido de um profundo diálogo entre várias culturas, através de mediações e apropriações que colocam em cheque os sentidos envolvidos nesse trânsito. As encenações e os textos dramáticos têm buscado sintetizar o movimento globalizante que caracteriza as últimas décadas, levando para o primeiro plano os problemas implicados nos choques culturais presentes na vida cotidiana, seja pela presença física do outro (via fluxos internacionais de pessoas), seja pela presença simbólica, inscrita nas imagens, sons e palavras que circulam pelos meios de comunicação.

Embora seu foco seja o teatro europeu das últimas décadas (de Artaud a Barba e Mnouchkine), e em como esses artistas colocaram em cena, de diferentes modos, o problema das relações interculturais, Pavis pretende estabelecer uma teoria mais ampla dos processos artísticos - que, com pontuais alterações, pode ser aplicada à adaptação cinematográfica. Para definir esse encaminhamento teórico, Pavis afirma que "o termo interculturalidade parecenos adequado, melhor ainda que os de multiculturalismo ou transculturalismo, para nos darmos conta da dialética de trocas dos bons procedimentos entre culturas" (PAVIS, 2008, p. 2). Além disso, quando tratamos dos processos adaptativos, ocorre que, em geral, temos apenas duas matrizes culturais em contato (a do textofonte e a do filme adaptado), o que privilegia o uso do prefixo inter ("entre"), em vez dos prefixos multi ("vários") e trans ("através de”).

Por fim, uma terceira razão para investir no termo intercultural, quando estudamos esse tipo de adaptação, impõe-se de modo incisivo na metodologia que se propõe: uma vez que, historicamente, os estudos de adaptação foram marcados pelo método comparativo, embasado em categorias de análise vindas da intertextualidade, 
o salto que desejamos aqui demonstra exatamente essa mudança do intertextual para o intercultural. Ou seja, nosso desejo não é simplesmente comparar os filmes adaptados com os textos que lhes serviram de fonte; queremos, sobretudo, analisar como elementos fundamentais da cultura-fonte, em momentos sócio-históricos específicos, influenciam as escolhas estilísticas e linguísticas feitas no processo de adaptação.

Não queremos dizer aqui que um sobrevenha ao outro, no sentido de uma superação histórica. O estudo intertextual da adaptação leva em conta texto e filme, buscando semelhanças e diferenças em seus elementos estruturantes (trama, personagem, tempo, espaço, ação dramática etc.); por outro lado, o estudo intercultural da adaptação investe, a partir desses elementos estruturantes, em como a cultura-alvo medeia a transposição do texto-fonte no filme adaptado. O método intertextual, sem dúvida, ainda nos será válido, porém, queremos ir além, acrescentando aí a cultura como elemento definidor na criação dos sentidos dentro do processo adaptativo.

O modelo da intertextualidade, proveniente do estruturalismo e da semiologia, cede seu lugar ao da interculturalidade. Com efeito, não basta mais descrever as relações dos textos (e dos espetáculos), entender o seu funcionamento interno; é preciso da mesma forma, e acima de tudo, compreender a sua inserção nos contextos e culturas, bem como analisar a produção cultural que resulta desses deslocamentos imprevistos (PAVIS, 2008, p. 2).

A partir desses pressupostos, percebemos que a proposta teórica de Pavis, a meio caminho entre os estudos culturais e a semiótica da cultura, busca abarcar um conjunto amplo de experiências, vistas na especificidade do diálogo intercultural produzido no momento da realização tanto do texto dramático quanto da encenação desse texto. Assim, para entender esse diálogo e como ele influencia diretamente o produto artístico a ser criado, Pavis sugere a metáfora da ampulheta, como um objeto para simbolizar o trânsito de uma cultura a outra. "Na bola superior [da ampulheta] 
encontra-se a cultura estrangeira, a cultura-fonte que está mais ou menos codificada e solidificada em diversas modelizações antropológicas, socioculturais e artísticas" (PAVIS, 2008, p. 3). Na bola inferior, paralelamente, está a cultura-alvo, que recebe e "resignifica" os elementos que atravessam o gargalo e decanta-se no objeto artístico produzido. Esse processo, muito mais controlado pelo hemisfério inferior (ou seja, a cultura-alvo), está marcado pela capacidade da cultura-alvo de recorrer a elementos específicos da cultura-fonte, que condigam com suas preocupações estéticas e seus pressupostos socioculturais.

Assim, seja na campo da sociologia da cultura (WILLIAMS, 1979, 2000), da antropologia (WHITE, 2009) e dos estudos culturais (HALL, 2009; BHABHA, 2007), seja nos estudos sobre capitalismo cognitivo e biopoder (GORZ, 2003), a cultura parece ser um conceito central nas discussões contemporâneas. Temas como direitos autorais, software livre, reprodução digital de conteúdo, peer to peer e bens imateriais têm ocupado o primeiro plano das disputas - econômicas, políticas ou simbólicas - na arena social dos dias atuais, trazidas que foram pelas revoluções da tecnologia digital e pelo barateamento dos mecanismos de produção e reprodução de conteúdo. Esse lugar em que a cultura está posicionada foi conquistado por uma longa contenda teórica que revalorizou o conceito em diversas disciplinas e apontou para a sua centralidade - para retomarmos aqui o famoso texto do Stuart Hall (1997) - na sociedade contemporânea. Essa centralidade, no entanto, não significa que cultura seja um conceito unitário, sem divergências e variâncias, em torno do qual sobrevém um consenso absoluto. Muito pelo contrário, o conceito de cultura, desde sua origem, passou por diversas mudanças, a ponto de necessitarmos nos perguntar, dentro do modelo analítico que aqui propomos, o que entendemos por cultura.

\section{Em torno do conceito de cultura}

De fato, há hoje uma visão ampla de como o termo cultura ganhou vários sentidos com o caminhar dos séculos, moldandose em diversas dimensões conceituais e em campos diferentes das 
ciências humanas. Podemos iniciar por uma trilha etimológica, em que encontraremos que a palavra cultura, assim como culto e colonização, "derivam do mesmo verbo latino colo, cujo particípio passado é cultus e o particípio futuro é culturus" (BOSI, 1992, p. 11). A palavra inicialmente estava ligada às formas de cultivo da terra, de onde surge o seu sentido primevo: lembremos que o adjetivo referente ao substantivo agricultura é agrícola. Quando nos referimos ao particípio passado, cultus, queremos dizer que "a sociedade que produziu o alimento já tem memória” (BOSI, 1992, p. 13), ou seja, entre o colo e o cultus existe o processo, o cultivo, que faz que o trato da terra repita constantemente os seus frutos. Além disso, cultus quer dizer também o culto dos mortos, uma prática social de rememorar os que já partiram, como uma forma primeira de religião.

Consequentemente, o particípio futuro, culturus, remete àquela terra que ainda será tratada, aquilo que se vai ainda cultivar. Nesse sentido, o termo fora empregado para falar, de um lado, do cultivo do solo, substantivamente, e, de outro lado, do trabalho feito, desde a infância, no ser humano. "Cultura é o conjunto das práticas, das técnicas, dos símbolos e dos valores que se devem transmitir às novas gerações para garantir a reprodução de um estado de coexistência social. A educação é o momento institucional marcado do processo" (BOSI, 1992, p. 16). Cultura aqui, então, lidava não apenas com a materialidade do alimento mas também com os signos, com a palavra, com a educação.

Esse conceito de cultura, mais ou menos sem variações, perduraria até o século XVIII, quando ocorreu a emergência do conceito de civilização, que então deslocou a cultura para outro domínio. Até então, a ideia de civilização já era conhecida e aplicada, principalmente, com o sentido ligado a civil, ou seja, a educação e cortesia: uma pessoa civilizada era um sujeito polido, socialmente respeitável. Contemporânea ao desenvolvimento das sociedades modernas, a ideia de civilização se reconfigurou em dois outros conceitos, dando-lhe a nuança que se conforma até hoje: "um Estado realizado, que se podia contrastar com a barbárie, mas também agora um Estado realizado de desenvolvimento, que 
implicava processo histórico e progresso" (WILLIAMS, 1979, p. 19). Uma vez que, no século XVIII, "cultura" e "civilização" eram termos intercambiáveis, utilizados para falar de coisas semelhantes, houve portanto uma fusão das noções de cultura e de progresso. É nesses termos que compreendemos cultura num sentido valorativo, capitalizado: investe-se em cultura e dela se desprende um valor, um capital, e, quanto mais essa cultura se manifesta em conhecimento, tecnologia, ideias e práticas sociais produtivas, mais em direção ao progresso se parece caminhar.

Porém, uma ruptura entre civilização e cultura começou a germinar no seio das transformações sociais de fins do século XVIII e início do século XIX, imbricadas no Iluminismo francês, de um lado, e no Romantismo alemão, de outro. Nesse momento de mudança, o conceito de civilização, utilizado agora a partir da visada Imperialista (como em "civilizar os bárbaros"), passa a ser visto então como artificial, e o conceito de cultura foi se afastando dele, em favor da defesa dos valores humanos, marcando uma crítica à sociedade imperialista e tecnicista que se formava com a Revolução Industrial. Nesse momento, cultura passou a se referir às obras artísticas e manifestações intelectuais que investiam na natureza, nos valores humanistas e na interioridade do sujeito. Isso implicou diretamente que a cultura, posicionada agora numa arena de disputas, era composta por uma gama ampla e variada de significados. Foi, portanto, a partir dessas circunstâncias que cultura passou a ter um plural ("culturas"), visto que o caráter nacional, ligado às práticas artísticas e simbólicas próprias de um povo, tornouse central para o estabelecimento da diferença, seja entre culturas nacionais diversas (francesa, inglesa, portuguesa, brasileira), seja no interior de uma mesma cultura nacional, dividida agora em estratos classificatórios (alta e baixa culturas).

A tensão criada entre essas duas últimas visões do conceito de cultura - de um lado, aquela que abarca as artes e o intelecto, e, de outro lado, o modo de vida de um povo (hábitos, costumes, práticas) - é fundamental para entender a cisão entre o que modernamente se estabeleceu como alta cultura e baixa cultura. Nessa separação, é importante que enfatizemos, está inscrita uma mudança no estatuto 
da obra de um autor como William Shakespeare nas sociedades modernas: se inicialmente ligado à cultura popular (na dimensão contraditória que o fazia espetáculo para o mais humilde artesão e para a mais rigorosa rainha), Shakespeare passaria, a partir de fins do século XVIII, a ocupar o pedestal mais elevado da alta cultura anglófona, tornando-se então conteúdo curricular nas escolas, objeto de culto e adoração, símbolo nacional para as colônias. Isso significa que essa mudança no estatuto simbólico que o autor passou a ter dentro da comunidade anglófona está diretamente relacionada com a própria redefinição do conceito de cultura em favor de uma segregação valorativa que secciona a cultura em alta e baixa.

A partir da segunda metade do século XX, no entanto, houve uma nova mudança epistemológica no conceito de cultura, que Raymond Williams chama de uma "nova forma de convergência", ou seja, uma articulação entre os pressupostos sociais e a materialização das ideias que desemboca em novo conceito para a cultura, "em que a 'prática cultural' e a 'produção cultural' (seus termos mais conhecidos) não procedem apenas de uma ordem social diversamente constituída, mas são elementos importantes em sua constituição" (WILLIAMS, 1979, p. 12). E, mais adiante, o autor finaliza: "Em vez, porém, do 'espírito formador' que, afirmavase, criava todas as demais atividades, ela encara a cultura como o sistema de significações mediante o qual necessariamente (se bem que entre outros meios) uma dada ordem social é comunicada, reproduzida, vivenciada e estudada" (WILLIAMS, 1979, p. 13).

Foi no seio dessa nova concepção de cultura - em que não mais se cultiva ou se progride, mas se constitui e se medeia que se formaram os chamados Estudos Culturais, cujo cerne é precisamente estudar esse sistema de significações nos diversos contextos sociais em que são geradas e geradoras. $\mathrm{O}$ principal a enfatizar sobre este último sentido de cultura (e que nos será muito útil) é precisamente isso: os bens culturais (práticas, hábitos, formas, estilos, obras) não são apenas produtos do contexto social de onde se manifestam, mas, dialeticamente, eles também são formadores desse contexto, de modo vivo e orgânico. É o contrário da visão em que a cultura costuma ser concebida como o reflexo da sociedade: 
nesse novo sentido, a cultura é antes de tudo o próprio espelho, sem o qual essa sociedade não pode se ver - ou seja, ela não é só a imagem, mas a produtora dessa imagem.

Resumindo, podemos inferir que a cultura costuma, ainda hoje, ter os seguintes significados, que, embora diversos, não são excludentes e, em conjunto, formam a ideia conflituosa e cheia de variantes que temos atualmente:

(i) Um estado mental desenvolvido - como em "pessoa de cultura", "pessoa culta", passando por (ii) os processos desse desenvolvimento - como em "interesses culturais", "atividades culturais", até (iii) os meios desses processos - como em cultura considerada como "as artes" e "o trabalho intelectual do homem”. Em nossa época, (iii) é o sentido geral mais comum, embora todos eles sejam usuais. Ele coexiste, muitas vezes desconfortavelmente, com o uso antropológico e o amplo uso sociológico para indicar "modo de vida global" de determinado povo ou de algum outro grupo social (WILLIAMS, 2000, p. 11).

Para o que nos interessa neste artigo, portanto, corroboramos essa síntese de pressupostos que concebe a cultura não apenas como reflexo, mas como refletora das práticas sociais concretas, no seio da qual os signos transitam em constante mediação, esta aqui se referindo “aos processos de composição necessários, em um determinado meio; como tal, indica as relações práticas entre formas sociais e artísticas. Em seus usos mais comuns, porém, refere-se a um modo indireto de relação entre a experiência e sua composição" (WILLIAMS, 2000, p. 23). A cultura entendida, portanto, como mediação entre os contextos sociais e as práticas, hábitos, costumes e formas artísticas formadas em seu interior.

\section{Por um conceito de adaptação intercultural}

Chegando a essa síntese conceitual em torno das várias noções de cultura, cabe agora uma pergunta: como essa definição de cultura se insere no conceito aqui proposto de adaptação intercultural? Há diversos processos adaptativos em que a experiência intercultural 
se verifica de modo axiomático: no exemplo que trabalharemos neste artigo, quando pensamos em Shakespeare no cinema brasileiro, vemos que sua obra não partilha a mesma matriz da cultura adaptante, a mesma língua ou as mesmas ordens sociais representadas nem a ele atribui a importância de um símbolo nacional. No entanto, a sua presença como autor "estrangeiro" é de longe a mais significativa no cinema nacional - nem mesmo escritores portugueses de relevo como Camões ou Eça de Queiroz chegam perto do que Shakespeare representa em termos de adaptações cinematográficas. Com o conceito de adaptação intercultural, queremos propor que enxerguemos esses processos adaptativos em que há diferenças culturais exatamente como um prisma de mediação interposto entre texto-fonte e filme adaptado, cujos espelhos refratam os elementos estruturantes do texto-fonte em direção a novos sentidos cinematográficos, mediados por elementos culturais presentes na época e no contexto social durante o processo de adaptação.

A cultura, portanto, é esse interposto prismático que refrata os sentidos e reconfigura os aspectos determinantes do texto-fonte no filme adaptado, ou seja, na materialidade concreta da obra. Isso significa que, embora estejamos tratando de visões culturalistas e tocando em abordagens sociológicas que estudam o fazer artístico, nossa ênfase continua na centralidade da obra, em como ela sintetiza esses embates entre formas sociais e artísticas e em como o produto audiovisual concreto carrega, em sua materialidade, os signos do processo cultural de sua gênese. Por isso, estamos propondo um conjunto de categorias analíticas para o estudo, na leitura fílmicotextual das obras, de como a mediação da cultura brasileira ao adaptar Shakespeare - em suas mais variadas instâncias influenciou as escolhas das mudanças estilísticas entre texto e filme.

A partir da síntese de visões sobre a cultura e sobre os processos artísticos interculturais, precisamos agora de uma definição clara do conceito, aparentemente difuso, de adaptação intercultural aqui proposto; além disso, devemos estabelecer categorias de análise que deem conta dos principais aspectos que são alterados, enfatizando o modo pelo qual elementos estruturantes do texto-fonte têm os 
4. As dimensões do presente artigo não permitem analisar com profundidade cada uma das categorias de análise. A visão inicial de suas definições, portanto, servem como ponto de partida para estudos de caso específicos, tendo em vista o caráter epistemológico de proposição metodológica que define este artigo. seus sentidos reconfigurados quando são levados às telas. Podemos afirmar, em resumo, que a adaptação intercultural não se refere simplesmente aos processos de criação cinematográfica em que a fonte literária não possui a mesma origem cultural do filme adaptado; ao contrário: a adaptação intercultural refere-se aos casos em que texto-fonte e filme adaptado não surgem da mesma matriz cultural, e em que determinadas práticas sócio-culturais oriundas do contexto da adaptação medeiam reconfigurações de sentidos do textofonte, na materialidade estilística do filme adaptado.

Como se vê, não é o objetivo deste artigo apenas escolher um nome para chamar esse modo de adaptação em que o textofonte pertence a uma matriz cultural diferente do filme adaptado. Afinal, se pensarmos de uma maneira mais exagerada, podemos inferir que toda adaptação implica uma mudança cultural, nem que seja da cultura literária para a cultura cinematográfica cada qual empregando uma definição de cultura condizente com seus meios e formas de expressão. Antes de tudo, buscamos aqui entender conceitualmente o que chamamos de "reconfigurações de sentidos do texto-fonte", quando o processo de adaptação envolve produtos de culturas diferentes. São essas reconfigurações que estamos chamando de categorias de análise ${ }^{4}$, cuja eficiência deve ser posteriormente aplicada aos filmes brasileiros adaptados de Shakespeare, no sentido de auxiliar na compreensão desse tipo particular de adaptação.

Afinal, quando o caso é Shakespeare no cinema, não lidamos com filmes cujo processo adaptativo é necessariamente o mesmo ou melhor, vários deles parecem possuir propostas ontologicamente contrastantes: por exemplo, filmes adaptados de The tempest, derradeira peça de Shakespeare, como The tempest (dir. Percy Stow, 1908), Forbidden planet (dir. Fred McLeod Wilcox, 1956), The tempest (dir. Derek Jarman, 1979), Propero's books (dir. Peter Greenaway, 1991) e The tempest (dir. Julie Taymor, 2010), possuem modos tão diferentes de adaptar o texto shakespeariano que parecem exigir, cada qual, conceitos e ferramentas metodológicas específicos para a devida investigação. 
Se no primeiro filme, de 1908, enfatiza-se a análise dos processos adaptativos no cinema silencioso, estudando como a linguagem cinematográfica, naquele momento, carente de diálogo, era capaz de conceber uma determinada representação do texto shakespeariano, no último filme, de 2010, tende-se a enfatizar o deslocamento genérico na escolha de uma mulher para o papel de Próspero, inserido numa mise-en-scène fílmica que privilegia os grandes jogos de câmera e a utilização recorrente dos efeitos especiais num espetáculo imagético típico da Hollywood contemporânea.

Consideraremos, portanto, para a definição de categorias analíticas capazes de explicar o fenômeno da adaptação intercultural, os seguintes elementos estruturantes, que são reconfigurados em maior ou menor escala - na mudança não só de um meio a outro mas também de uma matriz cultural a outra: a língua falada; o cronótopo; a trama; as dominantes genéricas; e, finalmente, o estilo de encenação. No exemplo que estamos dando, em torno de Shakespeare no cinema brasileiro, cada um desses elementos deve ser visto na adaptação do texto ao filme através do prisma da cultura brasileira, que, com seus códigos e práticas historicamente determinados, refrata os sentidos do texto-fonte para que sejam inseridos em nosso ambiente cultural.

A primeira categoria, a língua falada, é a que, inicialmente, se mostra mais perceptível, embora não seja dominante principalmente, quando, na relação entre a cultura do colonizador e a do colonizado, as línguas costumam ser partilhadas. No caso de Shakespeare no cinema brasileiro, a análise deve sempre balizar como o inglês elisabetano do texto shakespeariano é traduzido para a língua portuguesa, com sotaques próprios, ligados ao contexto social em que a trama é inserida e ao estilo de encenação proposto pelos realizadores. Por exemplo, no filme $\mathrm{O}$ jogo da vida e da morte, de Mário Kuperman, o texto de Hamlet foi traduzido em uma linguagem mais coloquial, com gírias e palavrões condizentes com os personagens em seu lugar de existência. Podemos ter um pouco dessa dimensão no quadro comparativo (tabela 1) entre a 
fala do personagem João e a de Hamlet, no texto da peça. Não só no momento desse solilóquio mas em todo o filme, a tradução dos textos verbais revela bem o processo de adaptação intercultural. Por mais que se mantenham bastante próximas ao texto shakespeariano - com algumas supressões e acréscimos - , as falas do filme buscam, o tempo todo, transpor a linguagem de Shakespeare para uma dicção local, mais próxima do tipo de língua portuguesa falada pelos personagens na situação sociocultural em que estão inseridos. Assim, ouvimos várias gírias, termos coloquiais e até chulos, que auxiliam a superposição da trama shakespeariana ao contexto brasileiro em questão. E os solilóquios, tão presentes em Hamlet e tão importantes para transmitir as diversas camadas da sua subjetividade, são construídos no filme através da intercalação da voz em off, de planos ponto de vista e de monólogos diretos.

Em outro exemplo, no filme As alegres comadres, de Leila Hipólito, a trama shakespeariana foi inserida em Tiradentes no final do século XIX, em que os diálogos buscavam manter a estrutura frasal mais complexa da linguagem elisabetana (com inversões, metáforas e palavras já em desuso), e o personagem de Falstaff, por exemplo, possuía um carregado sotaque português que pretendia endossar sua fanfarronice. Ou seja, no estudo da adaptação intercultural, a língua em que são escritos os diálogos do filme (com suas especificidades de sotaque e estrutura) precisa ser analisada na busca de entender a mediação cultural brasileira na tradução de um texto tão carregado de nuances estilísticas e relevância artística quanto o de Shakespeare. 
Tabela 1

\begin{tabular}{|c|c|}
\hline O jogo da vida e da morte & Hamlet \\
\hline $\begin{array}{l}\text { Ser ou não ser, é esta a questão. } \\
\text { Será que é mais certo aceitar a } \\
\text { violência } \\
\text { Ou reagir e acabar com tudo isso? } \\
\text { Morrer, dormir, sonhar. } \\
\text { Ah, a morte! Será pior que a } \\
\text { porcaria dessa vida? } \\
\text { Se não, quem ia aguentar a } \\
\text { covardia dos mais fortes, } \\
\text { A tristeza do amor, a injustiça, as } \\
\text { leis, o coice dos inúteis? } \\
\text { Morrer. Fazer isso. É melhor não } \\
\text { arriscar o inferno? E viver? } \\
\text { A gente pensa, pensa e fica } \\
\text { covarde. } \\
\text { Não se arrisca e deixa de fazer o } \\
\text { que tem que ser feito. }\end{array}$ & 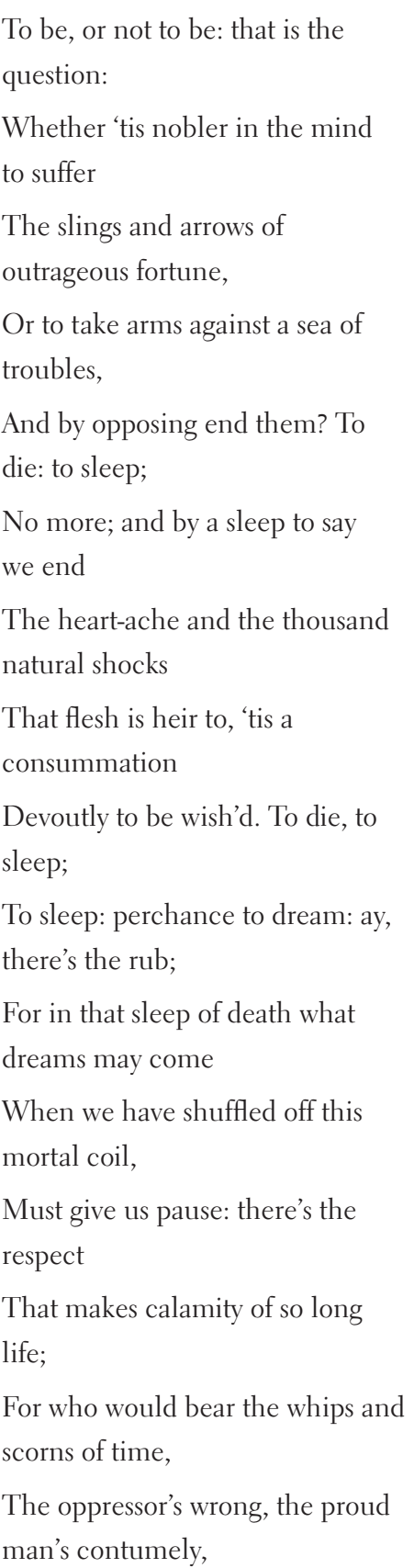 \\
\hline
\end{tabular}




The pangs of despised love, the
law's delay,
The insolence of office and the
spurns
That patient merit of the unworthy
takes,
When he himself might his quietus
make
With a bare bodkin? who would
fardels bear,
To grunt and sweat under a weary
life,
But that the dread of something
after death,
The undiscover'd country from
whose bourn
No traveller returns, puzzles the
will
And makes us rather bear those ills
we have
Than fly to others that we know
not of?
Thus conscience does make
cowards of us all;
And thus the native hue of
resolution
Is sicklied o'er with the pale cast of
thought,
And enterprises of great pith and
moment
With this regard their currents turn
And lose the name of action.


O cronótopo, a segunda categoria, pretende enfatizar o processo de "re-inserção" da trama do texto-fonte em uma unidade de tempoespaço que influencia direta e dialeticamente a própria definição do modo de adaptação. Afinal, ao utilizar como fonte as peças de Shakespeare - que se passavam em lugares como a Inglaterra, a Dinamarca, a Itália, o Chipre e uma ilha perdida no meio do mar — , os adaptadores costumam se deparar com duas perguntas: primeiro, devo alterar o tempo-espaço da encenação e, segundo, para onde e quando devo levar a história? No caso das adaptações interculturais, o cronótopo costuma sofrer alterações significativas, uma vez que se buscam novos contextos sócio-históricos sobre os quais as peças se sobrepõem, iluminando os sentidos dessa época e desse espaço. A herança, de Ozualdo Candeias, insere Hamlet no ambiente rural brasileiro durante a ditadura militar no país, fazendo do protagonista alguém capaz de se indignar com o problema da distribuição de terras e com a situação degradante dos trabalhadores rurais. Em Águia na cabeça, de Paulo Thiago, a história do desejo cego de poder em Ricardo III é transposta para o subúrbio do Rio de Janeiro nos anos 1980, em que o poder a ser almejado é o controle das bancas de jogo do bicho.

$\mathrm{Na}$ história de Shakespeare no cinema, temos mudanças cronotópicas célebres, que resultaram em obras muito relevantes, como Trono manchado de sangue e Ran, de Akira Kurosawa, Dez coisas que odeio em você, de Gil Junger, e Hamlet, de Michael Almereyda. Em todos esses exemplos, a mudança cronotópica se explica exatamente pela interposição prismática de códigos culturais específicos entre o texto-fonte e o filme adaptado. Por isso, devemos sempre refletir sobre o processo adaptativo como uma forma de utilizar o outro para falar de si mesmo, de seu tempo, seu povo e sua cultura.

$\mathrm{Na}$ terceira categoria, a trama, costumam ocorrer mudanças significativas no desenvolvimento dramático das histórias, com supressão ou adição de cenas e personagens e, consequentemente, com reconfiguração dos sentidos da peça. Um exemplo ilustre nesse caso é o filme alemão Hamlet: The drama of vegeance, de Sven Gade, em que a trama da peça é completamente transfigurada, 
fazendo que o protagonista seja, na verdade, uma mulher, criada como homem pelo medo de sua mãe, Gertrudes, de não ter um herdeiro masculino caso o Rei tenha morrido na guerra com a Noruega. Essa mudança radical na trama da peça reconfigura uma série de sentidos comumente ligados a Hamlet, como o papel ativo do protagonista na vingança, a relação afetiva com o pai e os papéis de Ofélia e Horácio (aqui, representando os conflitos sexuais de Hamlet). Transformações como essa, em geral, tendem a impor reconfigurações em outros aspectos do texto-fonte, como o desenho dos personagens e a dinâmica interna do protagonista consigo próprio e com os outros. Nesse sentido, abordar as transformações no universo da trama pode demandar ferramentas metodológicas comuns às análises comparativas de cunho intertextual - e, como dissemos anteriormente, os pressupostos da adaptação intercultural não suprimem, necessariamente, a abordagem intertextual. Porém, devemos enfatizar que o estudo comparativo deve ser utilizado não como fim, mas como meio, ou seja, como uma forma de iluminar questões no campo das transformações culturais que não se limitam aos textos, mas que neles estão circunscritas.

A quarta categoria, as dominantes genéricas, costuma estar diretamente relacionada com a anterior; ou seja, mudanças no gênero dominante do fílme, em relação ao texto-fonte, impulsionam reformulações na trama no sentido de adequar o conteúdo da história às novas especificidades genéricas que a estruturam. Uma vez que a questão do gênero, em Shakespeare, é muito atravessada pela constante mistura do trágico com o cômico em diversas peças, estamos chamando essa categoria de dominantes genéricas porque cada peça, ainda que trespassada por artifícios estilísticos mais próprios a outros gêneros, ainda mantém um definição genérica dominante. Ou seja, mesmo que Hamlet ou Rei Lear sejam exemplos sintomáticos da utilização de elementos cômicos, elas ainda assim não deixam de ser, dominantemente, tragédias. Por isso, na análise de filmes que, ao adaptarem Shakespeare, levam a trama e o destino dos personagens do polo trágico ao cômico, devemos atentar como os elementos da cultura-alvo medeiam essa transformação. No caso brasileiro, temos toda uma tradição de versões cômicas de Romeu e Julieta, que vem desde o filme seminal 
de Generoso Ponce, em 1924, e se tornou signo forte de nossa cinematografía com a cena do balcão protagonizada por Oscarito e Grande Otelo no filme Carnaval no fogo, de 1949, dirigido por Watson Macedo. Essa tradição se prolonga até os filmes mais recentes Didi, o cupido trapalhão e O casamento de Romeu e Julieta, que se caracterizam exatamente a partir dessas transformações nas dominantes genéricas, da mediação da cultura brasileira em cada contexto de adaptação e do diálogo estabelecido com a tradição.

Aquinta eúltima categoria, que chamamos de estilode encenação, enfatiza um elemento central da linguagem cinematográfica: a mise-en-scène. Com ela, pretendemos observar a maneira como a dramaturgia shakespeariana, nos filmes adaptados, é transformada em um modo particular de encenação, com procedimentos estilísticos oriundos de estruturas simbólicas importantes, como o projeto autoral, a época histórica e o sistema de produção. Além disso, o estilo de encenação está também diretamente vinculado à categoria anterior, visto que o gênero também influencia a definição dos elementos da mise-en-scène fílmica. Nesse sentido, devemos aqui procurar entender como os artifícios estilísticos próprios à linguagem cinematográfica auxiliam a transposição das peças de Shakespeare para os diferentes ambientes socioculturais brasileiros encenados nos filmes. No exemplo já citado de As alegres comadres, a transposição do enredo da peça para a Tiradentes de fins do século XIX é feita através da utilização de recursos da comédia televisiva — de onde vem a maioria dos atores presentes em cena - , em que, por exemplo, o encontro entre os apaixonados Franco e Ana Lima (mudança nominal dos personagens Fenton e Anne Page, do textofonte) é sempre acompanhado de uma trilha sonora leve e amorosa, numa espécie de leitmotiv reiterativo mais afeito às canções-tema presentes nas telenovelas, até porque a mesma música toca em todos os encontros entre esses personagens. Isso significa que o estilo de encenação do filme incorpora procedimentos estilísticos de um modo de comédia típico da televisão brasileira, numa busca deliberada - e, por sinal, fracassada - de alcançar com o filme um público mais amplo e popular. 


\section{Considerações finais}

As cinco categorias aqui propostas fazem parte de um caminho metodológico para o estudo de filmes adaptados cujos textosfonte se originam de matrizes culturais marcadamente diversas, a partir dos pressupostos teóricos daquilo que chamamos de adaptação intercultural. Nossa busca por conceitos e categorias próprios parte da observação de que, com a utilização irrestrita do método textual-comparativo comumente aplicado aos estudos de adaptação, as análises não são capazes de explicar os fluxos de sentido em choque, dentro da materialidade dos filmes, no processo de transposição, por exemplo, da literatura dramática shakespeariana para o cinema brasileiro.

Procuramos, com este artigo, abrir o diálogo com outros estudos de adaptação, a partir de outros autores e matrizes culturais, a fim de reforçar a validade analítica das categorias propostas. Nosso objetivo, vale reforçar, não é apenas que essas categorias sirvam de guarda-chuva metodológico para uma explicação pragmática dos fenômenos da adaptação intercultural, mas que elas funcionem como um ponto de partida para os aspectos centrais desse processo, uma vez que cada caso, particularmente, vai ter mais destaque em um ou outro elemento (a língua falada, o cronótopo, a trama, as dominantes genéricas ou o estilo de encenação), o que deve sempre fazer emergir os motivos e os procedimentos implicados em cada adaptação.

Buscamos, assim, estabelecer uma especificidade metodológica para os casos de adaptação intercultural, mas não só isso: queremos, de modo contíguo, ilustrar como determinadas épocas e movimentos cinematográficos se relacionaram com a literatura (estilos, formas, autores) e, especificamente, com a literatura estrangeira. Afinal, como afirma Patrice Pavis,

a transferência cultural não apresenta um escoamento automático, passivo, de uma cultura para outra. Ao contrário, é comandada muito mais pela bola "inferior" 
Adaptação intercultural: em busca de um modelo analítico | Marcel Vieira Barreto Silva

da cultura-alvo e que consiste em ir procurar ativamente na cultura-fonte, como que por imantação, aquilo de que necessita para responder às suas necessidades concretas.

(PAVIS, 2008, p. 3)

No caso de Shakespeare no cinema brasileiro, não se está apenas estudando como Shakespeare é adaptado no Brasil, mas - e alterando aqui o sujeito da frase - como e por que o Brasil adapta Shakespeare. 


\section{Referências}

ALLEN, G. Intertextuality. Nova York: Routledge, 2000.

BHABHA, H. O local da cultura. Belo Horizonte: UFMG, 2007.

BORDWELL, D. Narration in fiction film. Wisconsin: University of Wisconsin Press, 1985.

BOSI, A. Dialética da colonização. São Paulo: Companhia das Letras, 1992.

CORRIGAN, T. Film and literature: an introduction and reader. New Jersey: Prentice Hall, 1998.

COSTA, F. C. O primeiro cinema: espetáculo, narração, domesticação. São Paulo: Editora Scritta, 1995.

DEBBS, S. Cinema e literatura no Brasil - Os mitos do Sertão: emergência de uma identidade nacional. Fortaleza: Interarte, 2007.

GENETTE, G. Palimpsestes: la littérature au second degré. Paris: Éditions du Seuil, 1982.

GORZ, A. Metamorfoses do trabalho: crítica da razão econômica. São Paulo: Annablume, 2003.

HALL, S. “A centralidade da cultura: notas sobre as revoluções culturais do nosso tempo". Educação ๒ Realidade, Porto Alegre, v. 22, n. 2, p. 15-46, jul./dez. 1997.

Da diáspora: identidades e mediações culturais. Belo Horizonte: UFMG, 2009.

HUTCHEON, L. A theory of adaptation. New York: Routledge, 2006.

MACHADO, A. Pré-cinemas e pós-cinemas. Campinas: Papirus, 2007.

PAVIS, P. O teatro no cruzamento de culturas. São Paulo: Perspectiva, 2008.

SANDERS, J. Adaptation and appropriation. New York: Routledge, 2006. 
SILVA, M. V. B. "Adaptações literárias no cinema brasileiro contemporâneo". Revista Rumores, São Paulo, ano 2, edição 4, n. 2, 2009.

STAM, R. "Beyond fidelity: the dialogics of adaptation". In: NAREMORE, J. (Org.) Film adaptation. New Brunswick: Rutgers University Press, 2000.

Literature through film: realism, magic, and the art of adaptation. Malden: Blackwell Publishing, 2005.

Subversive pleasures: Bakhtin, cultural criticism and film. Baltimore: Johns Hopkins University Press, 1989.

WILLIAMS, R. Cultura. Rio de Janeiro: Paz e Terra, 2000. Marxismo e literatura. Rio de Janeiro: Jorge Zahar Editora, 1979.

WHITE, L. O conceito de cultura. Rio de Janeiro: Contraponto, 2009.

WOOLF, V. "The cinema”. In: WOOLF, V. The captain's death bed and other essays. London: The Hogarth Press, 1950. 